\title{
THE EFFECT OF TEMPERATURE GRADIENTS ON THE EXHALATION RATE OF RADON GENERATED BY BUILDING MATERIALS
}

\author{
Marius-Lucian BOTOȘ, ${ }^{1}$ Zsombor KISFALUDI-BAK ${ }^{2}$ \\ ${ }^{1}$ Technical University of Cluj-Napoca, Faculty of Civil Engineering, Department of Structural Mechanics, \\ Cluj-Napoca, Romania, marius.botos@mecon.utcluj.ro, zsombor.kisfaludi@mecon.utcluj.ro \\ ${ }^{2}$ Babeș-Bolyai University of Cluj-Napoca, Faculty of Environmental Science and Engineering, "Constantin \\ Cosma" Radon Laboratory, Cluj-Napoca, Romania
}

\begin{abstract}
There is increasing interest in indoor air quality studies. The effect of exhaled radon from soil, walls and ceilings has well-known consequences on human health, so the importance of modelling has been established. The present paper examines radon exhalation, on the one hand, only in the case of diffusion and, on the other hand, diffusion and advection. Comparing the results of the two test types, we can determine how significant the effect of temperature gradients on radon exhalation is. For a broader investigation, we performed the parametric tests on several types of material, wall thickness and radon concentration.
\end{abstract}

Keywords: radon, exhalation, air quality, $C F D$.

\section{Introduction}

In case of long-term exposure to radon there is an increased risk of developing lung cancer. There is considerable public concern about finding the sources of radon exhalation. Generally, radon enters the living spaces through cracks and gaps in basement areas, but in the case of new, air tight homes the building materials can add to indoor radon levels [1].

This study represents a small part of a multidisciplinary project which aims to investigate the indoor air-quality by modeling radon transportation. This transportation can be achieved in two ways (and combined): by diffusion and by advection - depending on the gradients of concentration or pressure. (Figure 1.)

Energy efficient homes need to have controlled ventilation in order to minimize the loss of accumulated or produced energy. Low air exchange with exterior can produce a decrease in air quality. Air proofing the basement area can lead to low radon concentrations in living areas, but the sources from building materials may lead to unexpected results. Air exchange remains import- ant, controlling it can improve the air quality and decrease radon concentrations.

When radon is exhaled from building materials and structural elements, the pressure gradient depends on temperature differences and the presence of wind that appears on the exterior walls. Depending on this pressure gradient and on the permeability coefficient of the wall, the presence of velocity can no longer be neglected

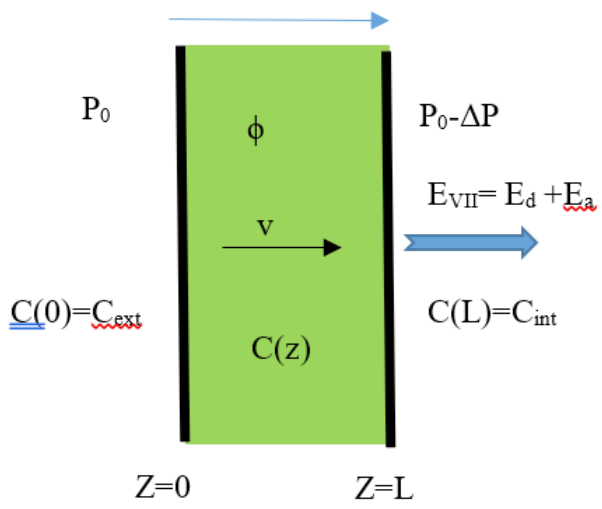

Figure 1. Factors on exterior wall, pressure gradi-ent (dependent on the temperature gradi-ent and wind velocity) 
so the radon transport equation also receives the advection term:

$$
\frac{D_{e}}{\varepsilon} \frac{\partial^{2} C}{\partial z^{2}}-\frac{1}{\varepsilon} \frac{\partial(v C)}{\partial z}-\lambda C+\phi=0
$$

The Darcy velocity inside of the porous element remains constant in the conditions of the incompressible air, the pores are non-deformable and the density of the mixture of radon-air is constant (2):

$$
\frac{D_{e}}{\varepsilon} \frac{\partial^{2} C}{\partial z^{2}}-\frac{v}{\varepsilon} \frac{\partial(C)}{\partial z}-\lambda C+\phi=0
$$

The roots(3) of the characteristic equation are real and different. The general solution of the radon transport equation under stationary conditions can be observed at equation (4).

Applying (6)(7) the boundary conditions (5) the system can be solved.

The exhalation rate is obtained by deriving the solution at the face of the element(8).

$$
r_{1,2}=\frac{-B \pm \sqrt{B^{2}-4 A C}}{2 A}=\frac{\left(\frac{v}{\varepsilon}\right) \pm \sqrt{\left(\frac{v}{\varepsilon}\right)^{2}+4 \frac{\lambda D_{e}}{\varepsilon}}}{\frac{2 D_{e}}{\varepsilon}}
$$

$C(z)=C_{1} e^{r_{1} z}+C_{2} e^{r_{2} z}+\frac{\phi}{\lambda}=C_{1} e^{\frac{\left(\frac{v}{\varepsilon}\right)+\sqrt{\left(\frac{v}{\varepsilon}\right)^{2}+4 \frac{\lambda D_{e}}{\varepsilon}}}{\frac{2 D_{e}}{\varepsilon}} z}+C_{2} e^{\frac{\left(\frac{v}{\varepsilon}\right)-\sqrt{\left(\frac{v}{\varepsilon}\right)^{2}+4 \frac{\lambda D_{e}}{\varepsilon}}}{\frac{2 D_{e}}{\varepsilon}} z}+\frac{\phi}{\lambda}$

$$
\begin{aligned}
& \left\{\begin{array}{l}
C(0)=C_{\text {ext }} \quad C_{\text {ext }}=C_{1} e^{0}+C_{2} e^{0}+\frac{\phi}{\lambda} \\
C(L)=C_{\text {int }} \quad C_{\text {int }}=C_{1} e^{r_{1} L}+C_{2} e^{r_{2} L}+\frac{\phi}{\lambda}
\end{array}\right. \\
& \left\{\begin{array}{l}
C_{\text {ext }}=C_{1}+C_{2}+\frac{\phi}{\lambda} C_{1}=C_{\text {ext }}-C_{2}-\frac{\phi}{\lambda} \\
C_{\text {int }}=\left(C_{\text {ext }}-C_{2}-\frac{\phi}{\lambda}\right) e^{r_{1} L}+C_{2} e^{r_{2} L}+\frac{\phi}{\lambda}
\end{array}\right.
\end{aligned}
$$$$
C_{2}=\frac{C_{i n t}-\left(C_{e x t}-\frac{\phi}{\lambda}\right) e^{r_{1} L}-\frac{\phi}{\lambda}}{e^{r_{2} L}-e^{r_{1} L}}
$$$$
C_{1}=C_{e x t}-\frac{C_{i n t}-\left(C_{e x t}-\frac{\phi}{\lambda}\right) e^{r_{1} L}-\frac{\phi}{\lambda}}{e^{r_{2} L}-e^{r_{1} L}}-\frac{\phi}{\lambda}
$$

$$
C(z)=\left(C_{e x t}-\frac{C_{i n t}-\left(C_{e x t}-\frac{\phi}{\lambda}\right) e^{r_{1} L}-\frac{\phi}{\lambda}}{e^{r_{2} L}-e^{r_{1} L}}-\frac{\phi}{\lambda}\right) e^{r_{1} z}+\left(\frac{C_{i n t}-\left(C_{e x t}-\frac{\phi}{\lambda}\right) e^{r_{1} L}-\frac{\phi}{\lambda}}{e^{r_{2} L}-e^{r_{1} L}}\right) e^{r_{2} z}+\frac{\phi}{\lambda}
$$

\section{2. . Parametric study}

In order to highlight the effect of advection / convection in addition to diffusion on the exhalation rates through brick and concrete walls and slabs, a parametric study was conducted. The materials used in these building structural elements are brick and concrete. Radon exhalation rates from concrete elements depends on the concrete age, porosity, air humidity, type of concrete and air temperatures [2].

If the elements were considered perimetral then the external concentration was considered to be 0 , for indoor faces of elements the radon concen- trations were equal to: 50, 100, 300, 500 and 1000 $\mathrm{Bq} / \mathrm{m} 3$.

The elements were considered to be $10,15,20$, 25 and $30 \mathrm{~cm}$ thick. The radon generation rate for these two materials was considered as average values (average for radium concen-tration, density, emission factor and porosity) from the literature [3] Thus for brick $\Phi=0,083 \mathrm{~Bq} / \mathrm{m}^{3} \mathrm{~s}$ and for concrete $\Phi=0,26 \mathrm{~Bq} / \mathrm{m}^{3} \mathrm{~s}$. In order to highlight the effect of the diffusion coefficient for these materials in the formation of the exhalation rates, has taken in turn values in the maximum minimum range (for brick between $8.4 \mathrm{e}-8$ and $3.4 \mathrm{e}-7 \mathrm{~m}^{2} / \mathrm{s}$; for concrete $2.1 \mathrm{e}-8$ and $5.2 \mathrm{e}-7 \mathrm{~m}^{2} / \mathrm{s}$ ). 
The exhalation rates for $10 \mathrm{~cm}$ and $25 \mathrm{~cm}$ brick and concrete wall are shown in Figure 2. and 3.

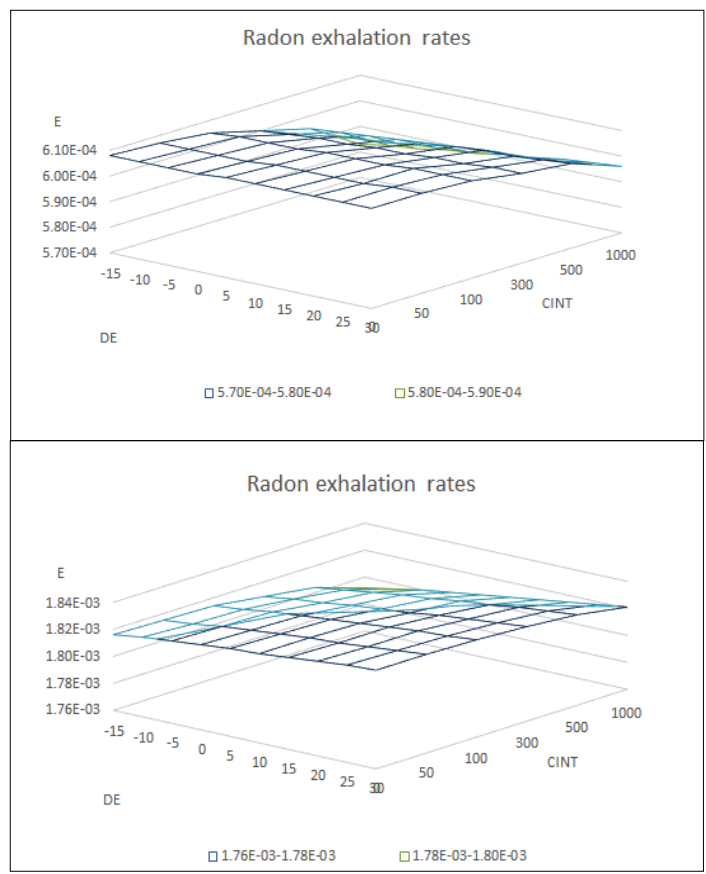

Figure 2. Exhalation rates in case of diffusion and advection for $10 \mathrm{~cm}$ brick (first) and concrete (second) walls

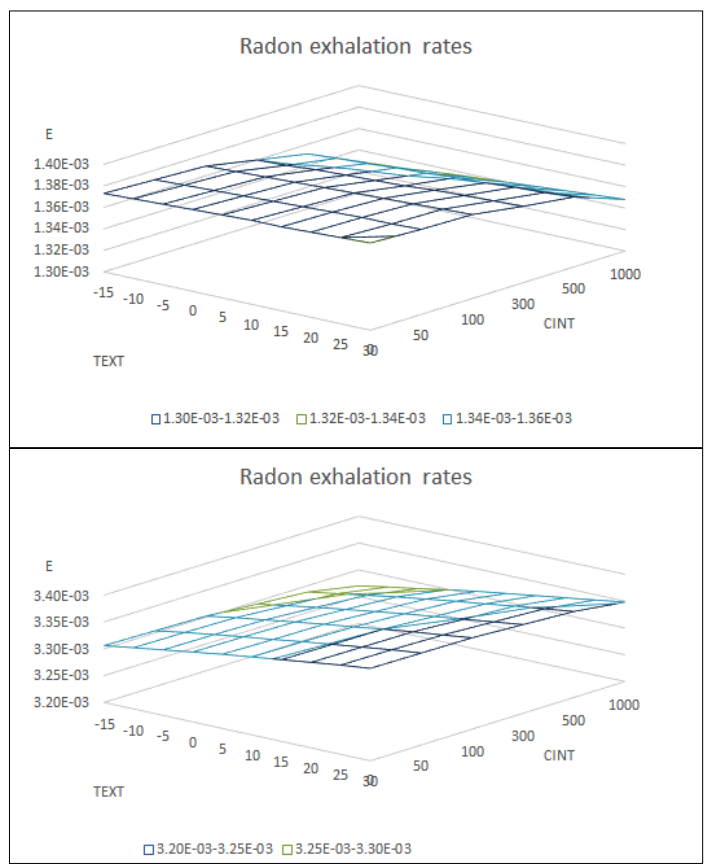

Figure 3. Exhalation rates in the case of diffusion and advection for $25 \mathrm{~cm}$ brick (first) and concrete (second) walls
The exhalation rates for $10 \mathrm{~cm}$ and $25 \mathrm{~cm}$ brick and concrete wall considering only the effect of diffusionare are shown in Figure 4. and 5.

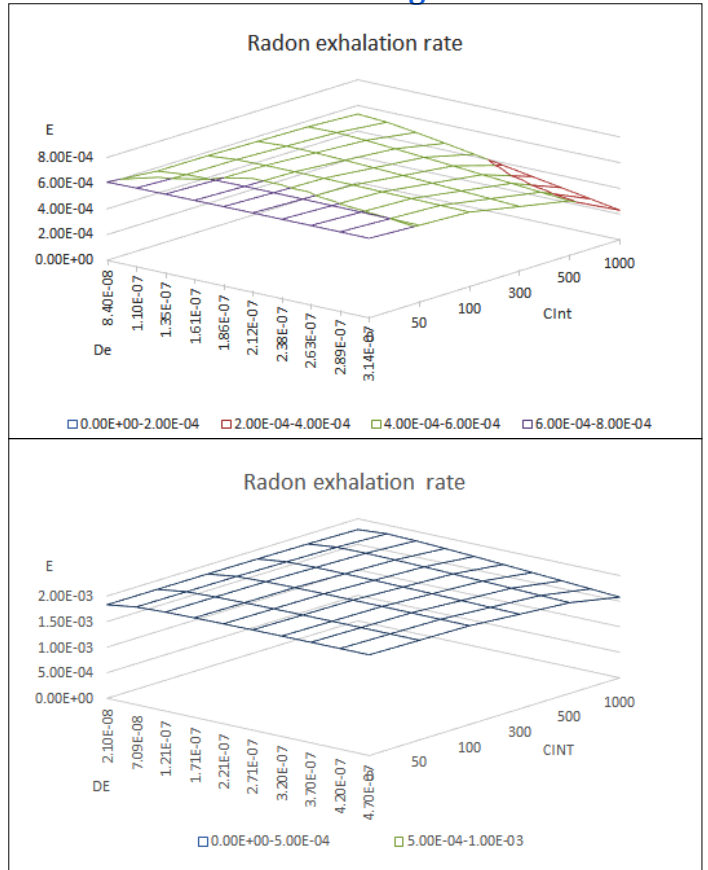

Figure 4. Exhalation rates in case of diffusion only for $10 \mathrm{~cm}$ brick (first) and concrete (second) walls

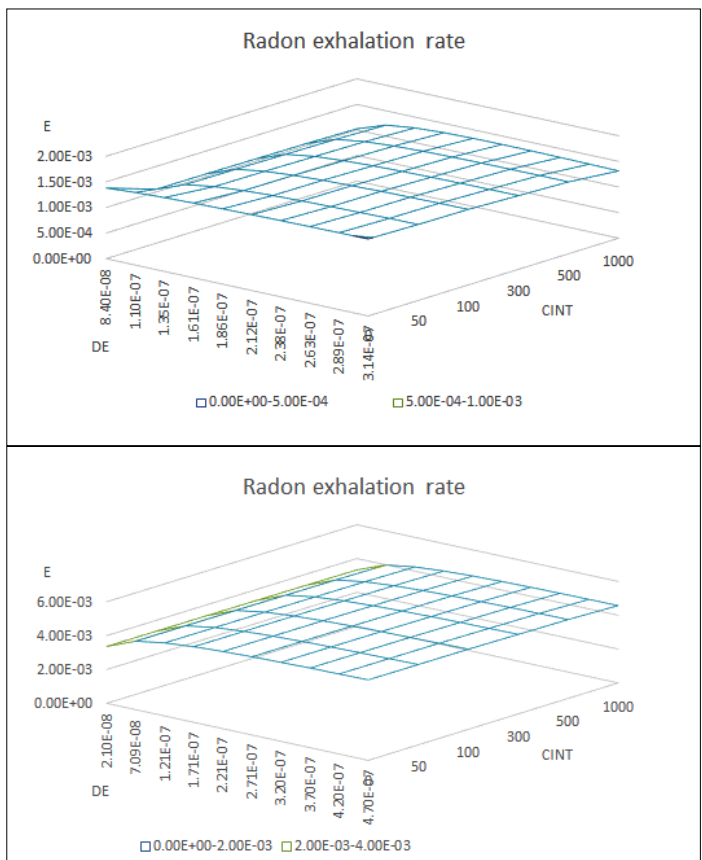

Figure 5. Exhalation rates in the case of diffusion only for $25 \mathrm{~cm}$ brick (first) and concrete (second) walls 
The results were obtained through the Ansys interface, and a series of UDFs were written for iterative generation of results in CSV format.

\section{Conclusions}

Differences recorded with the temperature gradients are insignificant, pressure differences generated by outside temperatures are far too small, and the permeability of the elements is too low for the advective term in the transport equation to become defining in the calculation of the exhalation rates.

\section{Acknowledgements}

This work was supported by the project ID P_37_229, Contract No. 22/01.09.2016, with the title „Smart Systems for Public Safety through Control and Miti- gation of Residential Radon linked with Energy Efficiency Optimization of Buildings in Romanian Major Urban Agglomerations SMART-RAD-EN" of the POC Programme.

This work was also supported by the Collegium Talentum 2018 Programme of Hungary.

\section{References}

[1] Chen J., Rahman N. M., Abu Atiya I.: Radon exhalation from building materials for decorative use. Journal of Environmental Radioactivity 101/4. (2010) 17-22. https://doi.org/10.1016/j.jenvrad.2010.01.005

[2] Apostu A.: Radon transport through building materials. PhD Thesis, Babeș-Bolyai Bolyai University, Cluj-Napoca, Romania, 2011.

[3] Font Guiteras L.: Radon generation, entry and accumulation indoors. PhD Thesis, Universitat Autònoma de Barcelona, Spain, 1997. 